\title{
OTRO POEMA BILINGÜE DE JOSÉ MARÍA ARGUEDAS
}

JULIO E. NORIEGA

Knox College (Estados Unidos)

jnoriega@knox.edu

\section{RESUMEN}

Uno de los aspectos menos estudiado de la obra de Arguedas es la parte dedicada a la poesía, castellana y quechua, que el escritor peruano compuso de manera circunstancial y apelando a contextos y sentimientos relacionados con su propia realidad. El presente trabajo rescata y contextualiza un poema bilingüe de José María Arguedas titulado «Gabicha» y dedicado a su amiga Gabriela Heinecke. El texto permaneció inédito hasta el año 2000, publicado por Anita Kelley en una revista norteamericana de estudios prehispánicos, y se reedita ahora en castellano, con un estudio introductorio en el que se analiza la transcripción del documento original, las diferentes traducciones, la relación de Arguedas con los protagonistas o el destinatario del texto.

Palabras clave: Poesía bilingüe, quechua, «Gabicha», traducción, Kelley.

\section{ABSTRACT}

One of the lesser studied areas of the work of Arguedas is his bilingual poetry (Spanish and Quechua) which is written in a circumstantial manner appealing both to the contexts and feelings related to his own reality. This study centers on a bilingual poem by José María Arguedas dedicated to his friend Gabriela Heinecke titled «Gabicha». The text, unpublished until the year 2000, appeared in an article by Anita Kelley in an American journal of Pre-Hispanic studies. This poem is now re-edited in Spanish with an introductory study analyzing the transcription of the original document, the different translations and the relationship of Arguedas with the readers of the text.

Keywords: Bilingual poetry, Quechua, «Gabicha», translation, Kelley.

Cuando escribir en quechua era todavía un secreto que se guardaba entre familiares, amigos y conocidos, José María Arguedas empezó a publicar poesías bilingües en quechua y en español durante la última década de su vida, es decir, en la época en que ya había alcanzado prestigio como escritor de novelas y ensayos en castellano. Lo hacía de manera esporádica, en homenaje a países, inventos, artistas y amigos que habían suscitado su admiración. Sus mejores poemas, sin embargo, son aquellos que surgieron motivados por circunstancias muy particulares que le conmovieron o perturbaron. Así fue como escribió el poema manifiesto «A nuestro padre creador Túpac Amaru», precisamente «en los tristes días en que se mataba comuneros», y lo publicó después de asegurarse, confiado en la opinión de John Murra y Luis Valcárcel, de que no sería «interpretado como un llamado a la rebelión» ni de que al autor se le confundiría con un «apestado comunista» (Ver la carta que Arguedas le escribió a John Murra desde Lima, el 15 de agosto de 1962; Murra,
Julio Noriega

Es profesor de literatura hispanoamericana en el Knox College (Illinois, Estados Unidos). Su trayectoria profesional muestra una especialización en estudios críticos sobre literatura peruana, muy especialmente en literatura andina, sobre la que ha trabajado temas vinculados a la obra arguediana, a la poesía quechua contemporánea, Poesía quechua escrita en el Perú, Lima, Centro de Estudios y Publicaciones (CEP 1993), y a otros autores como José Carlos Mariátegui o Ugo Facundo Carrillo.
Otro poema bilingüe de José María Arguedas JULIO E. NORIEGA 


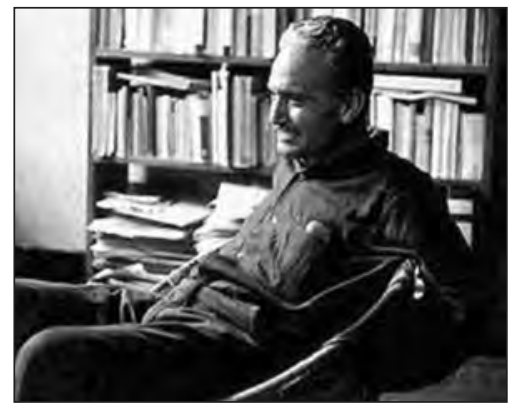

José María Argueda

1

Tal y como aparece, la nota aclaratoria que Arguedas incluye al final del poema es, en realidad, parte complementaria del texto poético en sí: «Escribí este himno luego de haber visto bailar a mis hermanos, hijos de pueblo de Ishua residentes en Lima. Bailaron en una pequeña habitación de adobes y techo de totora, en el canchón de la Av. Sucre, Pueblo Libre, el 3 de Setiembre de 1965» (José María Arguedas, 1983, p. 249)

2

Los diez poemas serían: 1) «A Francisco Miro Quesada C.», 2) «Harawi» (u "Oye Gertrudis»), 3) «Yawar qochapis kuntur wañuchkan/ Dicen que en un pozo de sangre», 4) «Tika, urpi, qaqa/ Flor, paloma, precipicio», 5) «Ama illarita manchacuychu/ No temas la luz del amanecer», 6) "Harawi: Ama k'onk'aychu, churiry/ No has de olvidarte hijo mío», 7) "Día y noche en tu puerta», 8) "Cerré la puerta, tras los hierros levantó su mano y sin despedirnos/ Cerré los ojos», 9| «Canción» y 10) otro poema, sin título, publicado formando parte de la novela Todas las sangres.

3

En el lado inferior derecho del manuscrito en quechua, Arguedas ha escrito su nombre: José María. Llama la atención que en sus cartas Arguedas haga comentarios sobre Gaby y, sin embargo, no mencione haber escrito este poema. (A partir de ahora me referiré al texto original y castellano con el número de página del artículo de Kelley).

Otro poema bilingüe de José María Arguedas JULIO E. NORIEGA
1998, p. 84). De la misma manera, la depresión que le sobrevino el año de 1965, a consecuencia del debate que sostuvo en el Instituto de Estudios Peruanos (IEP) con un grupo de intelectuales sobre la recepción de su novela Todas las sangres, motivó la apelación de «Llamado a algunos doctores». Por otro lado, con el ánimo que le infundió haber visto a sus «hermanos de Ishua» cantar y bailar, dentro de una «pequeña habitación de adobes y techo de totora» en el distrito de Pueblo Libre en Lima, compuso el himno «Katatay»1. Los poemas bilingües de Arguedas tienen, por consiguiente, un marcado carácter circunstancial, son poemas de ocasión y se ciñen, en su género, estructura y contenido temático, tanto a los hechos y propósitos que los motivaron como al destinatario concreto al que fueron dirigidos. Por eso, porque el mundo literario que representan no es propio ni independiente del de su contexto de elaboración, la lectura de cada uno de ellos exige que en el texto poético en consideración se incorporen aquellos datos de información paratextual.

\section{El hallazgo}

El corpus poético bilingüe perteneciente a Arguedas está en plena revisión. Además de los siete poemas reunidos en Katatay por Sybila Arredondo, en 1972, según el minucioso inventario bibliográfico realizado por Mauro Mamani (2011, pp. 55-56), ahora habría que considerar una decena más que se halla dispersa $^{2}$. A la propuesta de Mamani hay que agregar el poema «Gabicha», que Arguedas dedica a su amiga chilena Gabriela Heinecke, fechado el 21 de marzo de 1963, y se lo entrega personalmente en dos hojas escritas a mano, una en quechua y la otra en castellano. Este poema se mantuvo inédito hasta el año 2000 , fecha en que la traductora y latinoamericanista inglesa, Alita Kelley (2000, pp. 99113), lo publicó en una revista norteamericana de literaturas indígenas, reproduciendo el manuscrito original, agregándole otras versiones de transcripción e incorporando una traducción en español, con dos variantes diferentes a la del autor, y otra en inglés, a manera de difusión para el lector no hispanohablante ${ }^{3}$.

Alita Kelley acompaña la publicación del poema con un artículo de presentación en in- glés sobre la trayectoria literaria de Arguedas, cuyo éxito y reconocimiento en lengua castellana no significaron una realización plena hasta darse a conocer como poeta quechua en los últimos años de su vida y ver cumplido el sueño juvenil de escribir en quechua. En el artículo también informa de que obtuvo una fotocopia del original, escrito de puño y letra por el propio autor, en una visita que le hizo a Gabriela después de 26 años de no haberse visto. Al proporcionarle la copia, Gabriela le habría pedido a su amiga que le diera el tratamiento adecuado, «dado el interés que actualmente suscita el trabajo de Arguedas» (Kelley, 2000, p. 99). (La versión en castellano es mía). Desde entonces, Alita ha venido difundiendo el poema, además de publicarlo en la revista mencionada, cada vez que participa en conferencias y eventos relacionados con el tema.

\section{La transcripción}

El trabajo de transcripción se ha realizado con acierto y éxito en las distintas etapas de su desarrollo. A pesar de que la copia utilizada era borrosa, la versión mecanografiada del manuscrito que se reproduce garantiza con fidelidad el contenido tanto en quechua como en castellano. La naturaleza de texto bilingüe facilita, por suerte, despejar dudas, restaurar palabras ilegibles o verificar cualquier error mediante la comparación y el cotejo de las versiones en ambas lenguas.

Es práctico y recomendable para cualquier trabajo de este tipo que en la publicación se haya reproducido el original en versión bilingüe, acompañado de la transcripción hecha, para el caso del quechua, de una versión conforme a la grafía adoptada por el propio autor y de otra variante actualizada de acuerdo con las normas de la Academia de la Lengua Quechua (Cusco). De modo que los textos sirven de documento para que investigadores e interesados en la materia puedan hacer un seguimiento de los cambios realizados en cada uno de ellos, pero también para verificar si hubiera algún error o errata que enmendar. A simple vista se observa, por ejemplo, que en el tercer verso del poema transcrito en castellano se lee: «¿Cuántos ríos lloran ojos, hermanita?»(p. 107), el mismo que en el original de Arguedas aparece de manera correcta: «¿Cuántos ríos lloran en tus ojos, hermanita?» (p. 105). Las dificultades 
textuales que pudieran surgir se solucionan, pues, con el cotejo inmediato de las variantes que se encuentran a disposición.

\section{La traducción}

Prevalece en la traducción un criterio similar al utilizado en la transcripción: proporcionar al lector el mayor número de variantes posibles. El poema en castellano cuenta con tres versiones diferentes, una que pertenece al propio Arguedas y otras dos, a los esposos Gloria y Gabriel Escobar por separado. La traducción al inglés es, en cambio, una síntesis que trata de condensar lo mejor de todas las anteriores en castellano, aunque se advierte en la traductora, la misma Alita Kelley, una mayor inclinación a seguir el derrotero de Arguedas.

Sin embargo, ninguna de las dos traducciones a cargo de los Escobar logra captar el sentido poético que posee el original quechua. $\mathrm{Si}$ se trata de elegir o comparar versiones, éstas sirven más bien para ponderar y exaltar las virtudes de la traducción de Arguedas. Sin ánimo de examinar las traducciones en detalle, el equivalente que los tres traductores le dan a un verso en quechua ilustra lo señalado: «Pacha huntapa qawakunan ñawi» (p. 106). Para Arguedas es «ojos en que el mundo regocijado se contempla» (p. 107), Gabriel Escobar lo traduce como «Ojos para mirar todo el mundo» (p. 109) y, por su parte, Gloria Escobar opta por «Ojos que ven donde los mundos se encuentran» (p. 110). No es necesario discutir la confusión sintáctica y gramatical en la que caen los dos últimos porque ya Arguedas, en su traducción, identifica de manera precisa el sujeto y el objeto de la oración en quechua. No obstante, hay otro aspecto importante que señalar en cuanto al significado de "pacha hunta» en castellano. La traducción literal sería «mundo lleno», pero la que mejor se ajusta en este caso es «alegría, regocijo, felicidad o plenitud». Por tratarse de una lengua altamente metafórica y metonímica, según el consenso entre sus cultores, en el quechua abundan términos similares al indicado, cuya traducción a veces embellece el sentido de la palabra y otras se lo quita. El escritor Nilo Tomaylla, en una conferencia pronunciada en Ginebra, recuerda que, entre otras palabras y expresiones conocidas, "wiraqocha» significa etimológicamente «espuma del mar» y se

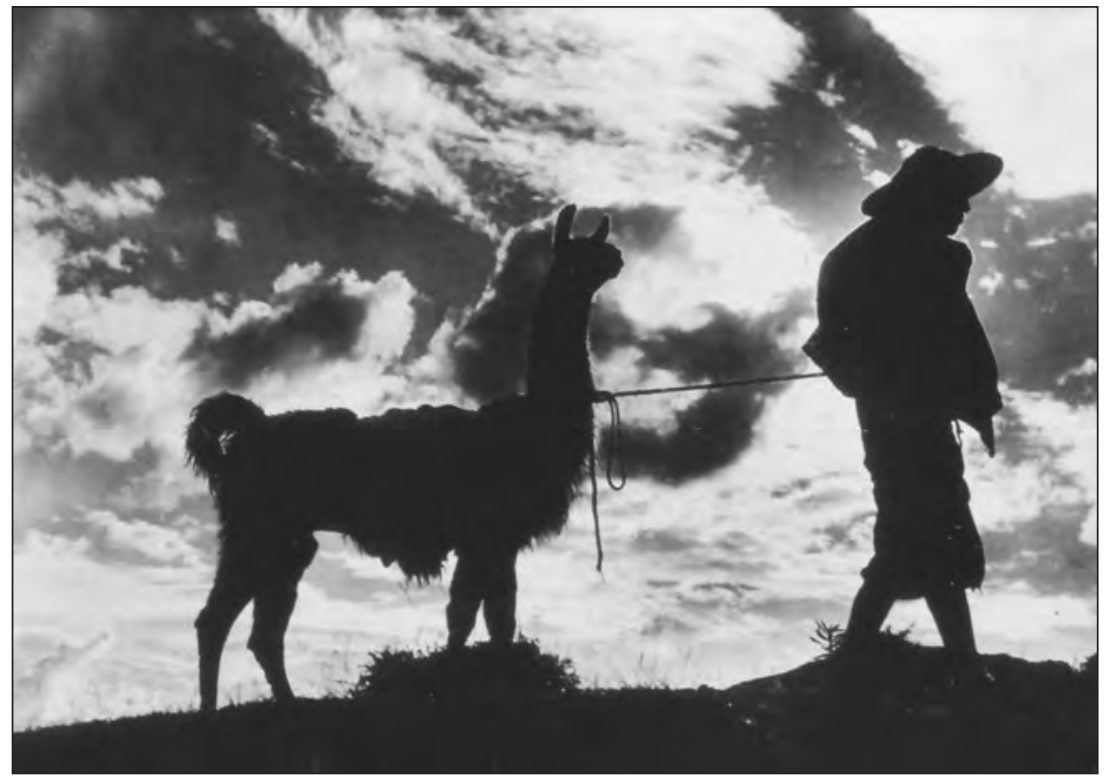

Imagen andina. Martín Chambi

traduce como «señor»; por el contrario, en «urpiq sonqon» los traductores conservan el equivalente de "corazón de paloma», cuando en verdad se trata de "generoso, bondadoso». (Nilo Tomaylla, 2011). Tal vez, la mejor explicación para este asunto se encuentre en las reflexiones de Edward Said (1983), cuando plantea el concepto de «metáforas viajeras» y afirma que también ellas viajan y en su recorrido migratorio no sólo pierden sino que ganan nuevos significados.

Como indica en su artículo Alita Kelley, traductora profesional con una formación teórica y práctica de muchos años, «la traducción es un acto imposible» (Kelley, 2000, p. 102). Ni la competencia lingüística y cultural, ni la formación profesional garantizan, a fin de cuentas, una traducción igual al original. Gloria y Gabriel Escobar son bilingües nativos, profesionales en el campo de la antropología y con amplia experiencia en la recopilación y traducción de huaynos quechuas al español. Arguedas tenía las mismas calificaciones que ellos, pero además contaba con la ventaja de ser un escritor maduro y experimentado. Al traducir sus poemas del quechua al español, no se limitó a la tarea de traductor, sino que ejerció el papel de poeta y el de traductor a la vez. No fue solamente un poeta quechua, como se dice con cierta ligereza, ni su poesía quechua, con la excepción de «Cubapaq», es monolingüe ${ }^{4}$. Él inauguró en el Perú la poética de la traducción para
Es el único poema que Arguedas dejó sin traducción al español. Si bien en algunos casos la traducción del resto de su producción no le pertenece, se sabe que participó en la revisión y corrección final de las pruebas. 


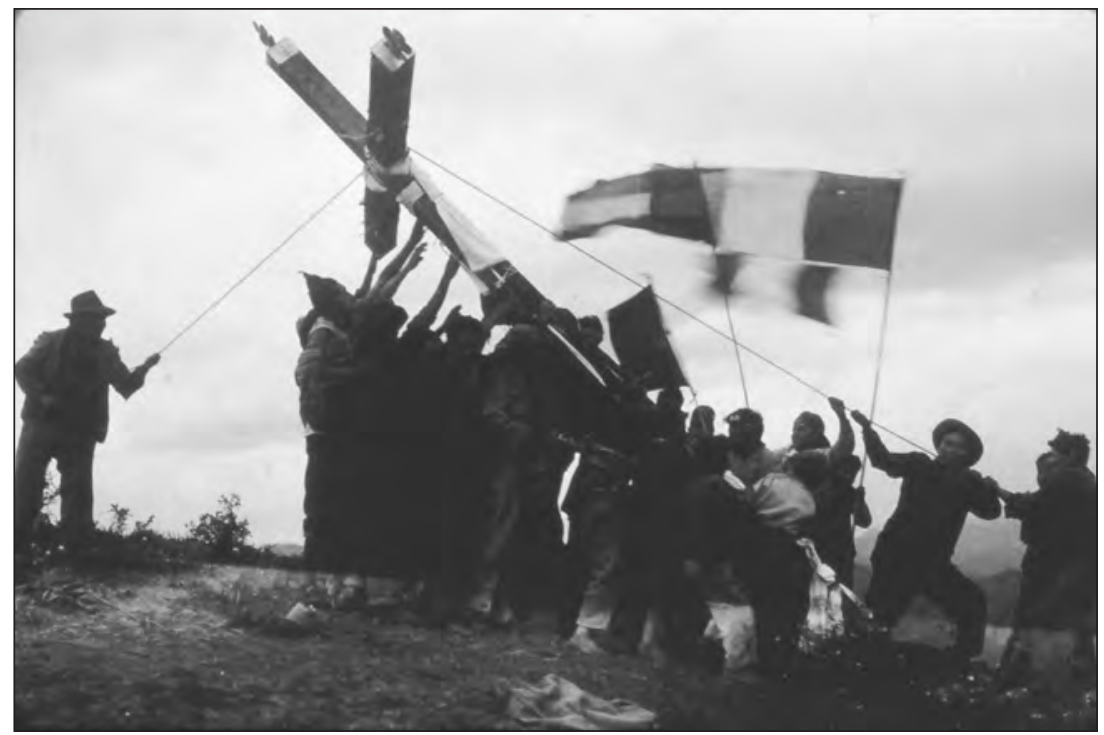

Imagen andina. Martín Chambi primacía de los poemas en quechua frente a sus equivalentes traducidos poéticamente o no al castellano.

\section{El poema}

El título del poema, "Gabicha», mantiene el nombre de la amiga de Arguedas, Gabriela Heinecke, a la que está dedicado. En su correspondencia, Arguedas se refiere a ella simplemente como Gaby, aunque es posible que, en una interacción familiar y personal, la llamara Gabicha en tono más íntimo y afectivo, ya que los unía una amistad muy estrecha y habían compartido temporadas largas en Chile, cuando Arguedas se hospedaba en su casa o en la de su madre, y en Lima, mientras Gabriela estuvo viviendo por un tiempo con la familia Arguedas: José María, Sybila y los dos hijos de ésta, Carolina y Sebastián.

La relación entre ambos amigos duró desde cuando se conocieron en 1962 hasta 1969, año en que murió Arguedas. Estuvieron juntos en momentos difíciles y padecieron problemas emocionales, aunque en distinto grado y por diferentes causas. En varias cartas escritas a su psiquiatra Lola Hoffmann, justamente entre 1962 y 1969, Arguedas le cuenta que anímicamente Gaby sufría, pero que en su casa de Santiago él se había sentido «como en un paraíso», en su madre Angélica había encontrado «algo de la imagen de la madre, y en Gaby a la hermana que nunca tuv[o]» (Murra, 1998, p. 69), cuidándolo «como ante un hermano herido» (Murra, 1998, p. 73).

La situación descrita en el párrafo anterior constituye uno de los ejes temáticos que se desarrolla en «Gabicha»: la hermandad y solidaridad andinas. El poema insiste en introducir otra noción de individuo y de su pertenencia. Gabicha, nombre propio, individual y que aparece acompañado de datos biográficos en el primer verso, se transforma en los siguientes versos en un nombre familiar, de naturaleza social y colectiva: "panichay». $\mathrm{Al}$ mismo tiempo, las categorías personales y las de posesión se definen por inclusión más que por exclusión, es decir, no hay el tú sin el yo, ni el mío sin el tuyo. En esta concepción del ser andino como dualidad o unidad complementaria, en el equilibrio de estar uno en alguien y ese alguien en uno, radica el español significa otra etapa de bilingüismo literario en la que se busca crear lectores en quechua y recuperar, al mismo tiempo, la 
principio de hermandad y solidaridad que se manifiesta en el poema.

En realidad, "Gabicha» es el poema de la personificación de un pueblo. En la voz poética se encarna implícitamente tanto la fuerza de la naturaleza como la visión animista del universo. Ante su mirada, Gabicha y el pueblo proyectan la misma imagen simbólica de caracteres comunes que los une. $\mathrm{Su}$ discurso, un diálogo mítico repleto de metáforas y metonimias, convierte a Gaby en alas de calandria, sus lágrimas y venas en ríos que corren por precipicios, el palpitar de su corazón en canto de palomas, el latir de su sangre en la fuerza del viento y el verde de sus ojos en el verde de los árboles y de otros elementos de la naturaleza que forman el pueblo del hablante o el Perú como nación. Entonces, ella no es únicamente la hermana o la mujer, sino también el pueblo peruano personificado, en cuyo cuerpo hay un mapa de la naturaleza viva, humanizada, $y$ en sus ojos cabe un mundo en el que se reflejan su propia vida y la del pueblo a la vez: «Yo escucho, hermanita, en tu vida, / todo el fuego hirviente de mi tierra» (Kelley, 2000, p. 107).

El núcleo en el que lingüística, estructural y temáticamente se organiza el poema está configurado con el verso de una sola palabra que aparece un poco después de la mitad: «Verden». Este término no existe en el vocabulario del quechua ni en el del español. Los diccionarios registran la palabra «birdi» para los dialectos quechuas que ya no conservan el vocablo original «q'omer» como el equivalente de verde. Arguedas, en desacuerdo desde el principio de su actividad literaria con cualquier postura purista, usa por ejemplo «cielo» dos veces a lo largo de la versión quechua de este texto, a pesar de la popularidad que goza «hanan pacha» cuando los hablantes se refieren al firmamento. También utiliza «q'omer» (verde) tres veces, una vez en la primera mitad y dos en la segunda. Pero «verden» ha sido creado como núcleo central a propósito, poéticamente, a partir de la experiencia personal de un escritor bilingüe en quechua y en español porque, al parecer, el verde («q'omer») en ninguna de las dos lenguas en contacto le proporcionaba aquello que el poeta buscaba transmitir: la comunión entre la naturaleza y el hombre, el individuo y el pueblo. «Verden» es, entonces, fonéticamente el punto de encuentro de las dos lenguas andinas, la distinción entre una parte del poema antes del núcleo verde y la otra después, aunque, en realidad, sirve mucho mejor de transición en la representación del color (que no es el verde en español ni el «q'omer» en quechua, sino «verden» en un quechuañol inventado por el autor) con el que al final logran integrarse la naturaleza y Gaby en una totalidad complementaria e intercambiable: «Verdes son,/ color hecho de la sangre de los peces, y de los patos que en/ grandes remansos juegan;/ verde de los inalcanzables árboles,/ color que no se piensa, verde del aire;/ ojos [los de Gaby] en que el mundo regocijado se contempla» (p. 107).

\section{El hermano}

Al darle a Gabicha el tratamiento de hermana («panichay»), la voz poética se identifica como su hermano (el «turichay» implícito $)^{5}$. El género en la lengua quechua se registra, a diferencia del español, sin recurrir a ningún tipo de flexión gramatical, ya que el léxico es el que marca esta distinción de manera pareada, un par de palabras para el uso exclusivo de las mujeres en su relación y otro par restringido al uso de los hombres, igual que en otros roles sociales dentro de una sociedad regida por el principio de la dualidad complementaria. Así, en el caso de las voces implicadas en este poema, a la mujer como emisor le corresponde el dualismo léxico de «ñaña/ turi» (hermana/hermano) y al varón el de "wayki/pani» (hermano/ hermana). Si la relación comunicativa se entablara, en cambio, entre seres del mismo género, «ñana» se reservaría para el femenino y para el masculino "wayki» ${ }^{6}$. Sin embargo, "wayki», como término quechua diacrónico en el mundo andino, ha adquirido un significado más amplio que el de su propio género, razón por la cual su aplicación comprende e incluye, en el contexto de las relaciones humanas en general, todas las otras acepciones. Durante el siglo XIX, desde la gesta de la independencia hasta la formación de la república de criollos, fue también, según lo manifestado en las proclamas, una metáfora de hermandad interétnica que, luego, cuando fracasa la promesa de convertir al indio en el hermano o amigo del criollo, desapareció de los programas políticos ante la idealización del inca
La variante léxica «pani» no pertenece al dialecto Cusco-Collao que en la suya tiene "pana» para hermana $y$ «tura» para hermano.

6

El Inca Garcilaso (1976, p. 190) explica de manera muy clara esta característica lingüística del quechua: "Para llamarse hermanos tienen cuatro nombres diferentes. El varón dice huauque: quiere decir hermano; de mujer a mujer dicen ñaña: quiere decir hermana. Y si el hermano a la hermana dijese ñaña (pues significa hermana) sería hacerse mujer. Y si la hermana al hermano dijese huauque (pues significa hermano) sería hacerse varón. El hermano a la hermana dice pana: quiere decir hermana; y la hermana al hermano dice tora: quiere decir hermano. Y un hermano a otro no puede decir tora, aunque significa hermano, porque sería hacerse mujer, ni una hermana a otra puede decir pana, aunque significa hermana, porque sería hacerse varón».

Otro poema bilingüe de José María Arguedas JULIO E. NORIEGA 


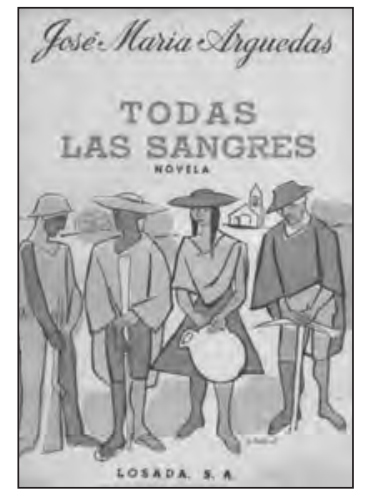

Otro poema bilingüe de José María Arguedas JULIO E. NORIEGA y la denigración del indio, a quien había que despojar de sus tierras y obligarle a olvidar su lengua y su cultura (Gonzalo Espino, 2007). Arguedas, en «Llamado a algunos doctores», levanta la voz del hermano y vuelve a reclamar la necesidad de forjar un Perú integral, el país de todas las sangres, que se sustente en el principio de la hermandad andina («wayquechallay»): «No, hermanito mío [doctor]. No ayudes a afilar esa máquina contra mí; acércate, deja que te conozca; mira detenidamente mi rostro, mis venas; el viento que va de mi tierra a la tuya es el mismo; el mismo viento respiramos; la tierra en que tus máquinas, tus libros y tus flores cuentas, baja de la mía, mejorada, amansada» (Arguedas, 1983, p. 255).

El principio de hermandad que postula «Gabicha» es muy distinto al que se ha manejado en los proyectos de nación. Recoge, más bien, una categoría relegada al ámbito local, comunal o arcaico, porque la base que lo respalda viene de la tradición del parentesco andino en el plano social y familiar del «ayllu». En este sentido, aunque no aparece la palabra «ayllu» en el texto, la noción intercambiable que se maneja para los términos colectivos de tierra, pueblo y Perú cabe como sinónimo de la institución que en la práctica, a costa de ciertas adaptaciones, ha sabido guiar, desde los tiempos preincaicos hasta estos días, los pasos de la asociación y organización de un gran sector de la población andina. Igualmente, los lazos que sirven de eslabón para que el pueblo pueda estar personificado en Gaby y, a su vez, ella sea parte de él, son similares a aquellos que emparentan a los miembros del «ayllu». Estos miembros creían descender de un mismo tótem, vivían de manera solidaria y se regían, de acuerdo al momento histórico, tanto por relaciones endogámicas como exogámicas. Por tanto, como una manera de reconocer la vigencia actual del modelo de parentesco social y familiar andino en busca de su propia modernidad, Gabicha y el sujeto de la voz poética terminan hermanados en una familia extensa («ayllu»), a pesar de haber nacido y crecido en pueblos diferentes, porque ambos son hijos de la madre Ángela, se conocen, ayudan y complementan, pero también porque el aire que respiran, el cielo que los creó, la vida y el color verde que los identifica con la naturaleza son los mismos.

\section{El destinatario}

Los poemas bilingües que escribió Arguedas están dirigidos, sin ninguna excepción, a un destinatario monolingüe hispanohablante o bilingüe en quechua y en español, pero nunca al monolingüe quechuahablante. En sus tiempos, era inconcebible ser leído en quechua, se consideraba ya bastante revolucionario, como observa Martin Lienhard, el simple hecho de escribir para demostrar ante los letrados limeños y la ola de inmigrantes andinos recién llegados, todos ellos víctimas del prestigio del español frente al quechua, que también en lenguas indígenas se podía volcar todo el caudal poético y mítico sobre el papel y el libro.

Ante sus destinatarios andinos y no andinos, Arguedas asume con orgullo el papel de embajador o representante del mundo quechua. A los no andinos les invita con sus poesías a andinizarse, a conocer mejor su realidad para apreciarla, y a los que ya lo son les exhorta a seguir cultivando el arte, la música y la literatura quechuas. En nombre del pueblo quechua, se solidarizó con la lucha que libraban cubanos y vietnamitas, felicitó a su querido "wayqe» Guayasamín e hizo un llamado a los académicos para que trataran de hermanarse con el hombre quechua. Gaby representaba, por su parte, el reto de un destinatario ideal no andino, a quien había que llegar con la palabra dulce y el mensaje redentor de los Andes. Para el escritor Arguedas, antes de su encuentro con esta amiga, existían, igual que en las niñas de Los ríos profundos, dos tipos de mujer como destinatario: la indígena a quien había que cantarle en quechua desde los caminos y la otra, la mujer no indígena, a la que había que escribirle cartas formales en español. Gaby no era peruana, sino extranjera; sin embargo, llevaba dentro un dolor profundo que la acercaba a la mayoría de las mujeres quechuas. Entonces, contenía las características de ambas mujeres: la indígena y la no indígena. Aunque no hablase quechua, representaba a la mujer a quien podía cantarle y escribirle a la vez, pero eso sí, valiéndose de la traducción poética. Por eso, además de ser un poema bilingüe, "Gabicha» es una carta poética e íntima que busca infundirle ánimos a su destinataria y hacerle sentir la fuerza regeneradora de la naturaleza cuando uno encuentra la manera eficaz de estar en perfecta comunión con ella y con su pueblo. 


\section{«Gabicha»}

Gabicha: cielo sonk'oyok', mamay Angelapa angel wawan

Haika mayukunatak' ñawikiypi wak'an, panichay;

Ima t'ikakunan llanllarin,

May urpikunan sonk'ochanwan takin.

Yawarniykin llak'taypa nunaywan,

Sachakunapa, manchay sumak'

k'ak'ankunawan hunt'asqa.

Uyarinin, panichay:

Tukuy ima llak'taypa tinpuk' kallpanni,

Kallpachisunkin, sirkaykipi rauran.

¡Raurachumpuni chek'ak'ta, ama llakipa, ama

manchaypa tukusk'an!

Panichay: tuyapa raphran, mayukunapa mosok'manta rurawask'an.

Cielo huntak' ñawikipin llak'taypa colornin

llipipin;

Q'omer alaymosca rumin,

Unupa mayllisk'a, apu mayupa

khuyapayasqan.

Verden.

Challwakunapa, chinkay patuchakunapa,

Yawarninmanta rurasqa q'omer;

Mana atiy sach'akunapa wayra q'omer;

Mana yachana, mana rimana;

Pacha huntapa qawakunan ñawi,

¡K'awaykullaway!

Kallpachakuy, panichay.

¡Yuyallaway!

Llak'taypa ununmi sonk'oykipi

yawarchakunk'a.

\section{Gabicha}

Gabicha, hija de mi madre Angela,

De su corazón que el cielo hizo.

¿Cuántos ríos lloran en tus ojos, hermanita?

¿Qué flores se encienden?

¿Qué palomas cantan con su pequeño corazón?

Tu sangre palpita con el aire de mi pueblo;

Tu sangre fue colmada por la belleza sin sosiego de los árboles y precipicios de mi pueblo.

Yo escucho, hermanita, en tu vida,

todo el fuego hirviente de mi tierra;

renacerá ese fuego en tus venas,

fortaleciéndolas, quemándolas,

Déjalo arder verdaderamente; quítale toda sombra de dolor y de miedo.

Hermanita: ala de calandria, nueva luz encendida por los grandes ríos;

En tus ojos que llenan los cielos, el color del Perú brilla; sus piedras verdes, alaymosca verde, por el agua purificada, amada de los ríos.

Verdes son,

color hecho de la sangre de los peces, y de los patos que en los grandes remansos juegan; verde de los inalcanzables árboles, color que no se piensa, verde del aire; ojos en que el mundo regocijado se contempla. ¡Mírame siempre!

Recoge el aliento de los poderes que en ti existen, hermanita.

¡Recuérdame siempre!

Todos los ríos de mi pueblo en ti pueden ser viva sangre.

(Kelley, 2000, pp. 106-107).

\section{Bibliografía}

Arguedas, José María (1983), Obras completas, Tomo V, Lima, Editorial Horizonte.

Espino, Gonzalo (2007), «Los hijos del Sol, del wawqi al indio» en Etnopoética quechua. Textos y tradición oral quechua. Tesis para optar el grado de Doctor en Literatura Peruana y Latinoamericana, Lima, Universidad Nacional Mayor de San Marcos.

Kelley, Alita (2000), "'Gabicha': An Unpublished Poem by José María Arguedas», Latin American Indian Literatures Journal, 16:2 (2000), pp. 99-113.

Mamami, Mauro (2011), José María Arguedas: Urpi, fieru, quri, sonqoyki. Estudio sobre la poesía de Arguedas, Lima, PETRO PERÚ, Ediciones Copé.

Murra, John y López-Baralt, Mercedes (1998), Las cartas de Arguedas, Lima, Pontificia Universidad Católica del Perú.

Said, Edward (1983), The World, the Text, and the Critic, Cambridge, Harvard University Press.

Noriega, Julio E. (1993), Poesía quechua escrita en el Perú, Lima, Centro de Estudios y Publicaciones (CEP).

Tomaylla, Nilo (2011), «Arguedas y la cultura andina», en [http://hawansuyo.blogspot. com/2011/11/arguedas-y-la-cultura-andina-nilo.html]

(Última consulta: 20/10/2012).

Vega, Inca Garcilaso (1976), Comentarios reales de los incas, Tomo I, IV, XI. Caracas, Biblioteca Ayacucho.

Fecha de recepción: 27/07/2012

Fecha de aceptación: 22/10/2012
Otro poema bilingüe de José María Arguedas JULIO E. NORIEGA 